\title{
OTTO (Ton), BORSBOOM (Ad), eds., Cultural Dynamics of Religious Change in Oceania
}

Leyde, K.I.T.L.V. Press (Koninklijk Instituut voor Taal, Land-en

Volkenkunde - Royal Institute of Linguistics and Anthropology), 1997, 144 p. (bibliogr., index)

\section{Éric Wittersheim}

\section{Q OpenEdition}

Édition électronique

URL : http://journals.openedition.org/assr/20805

DOI : $10.4000 /$ assr.20805

ISSN : $1777-5825$

Éditeur

Éditions de l'EHESS

\section{Édition imprimée}

Date de publication : 1 juin 2001

Pagination : 104

ISBN : 2-222-96704-X

ISSN : 0335-5985

Référence électronique

Éric Wittersheim, «OTTO (Ton), BORSBOOM (Ad), eds., Cultural Dynamics of Religious Change in Oceania ", Archives de sciences sociales des religions [En ligne], 114 | avril-juin 2001, document 114.33, mis en ligne le 19 août 2009, consulté le 21 septembre 2020. URL : http://journals.openedition.org/assr/ 20805 ; DOI : https://doi.org/10.4000/assr.20805

Ce document a été généré automatiquement le 21 septembre 2020.

(c) Archives de sciences sociales des religions 


\section{OTTO (Ton), BORSBOOM (Ad), eds., Cultural Dynamics of Religious Change in Oceania}

Leyde, K.I.T.L.V. Press (Koninklijk Instituut voor Taal, Land-en

Volkenkunde - Royal Institute of Linguistics and Anthropology), 1997, 144 p. (bibliogr., index)

\section{Éric Wittersheim}

\section{RÉFÉRENCE}

OTTO (Ton), BORSBOOM (Ad), eds., Cultural Dynamics of Religious Change in Oceania, Leyde, K.I.T.L.V. Press (Koninklijk Instituut voor Taal, Land-en Volkenkunde - Royal Institute of Linguistics and Anthropology), 1997, 144 p. (bibliogr., index)

1 Quand on parle de religion à propos de l'Océanie, on pense évidemment à Durkheim et aux Formes élémentaires de la vie religieuse, à Totem et tabou de Freud ou à la fameuse notion de "mana », mais beaucoup moins au christianisme. Depuis quelques années, l'anthropologie s'intéresse enfin aux religions importées qui ont profondément transformé le paysage des croyances et des pratiques religieuses dans le Pacifique. La question de l'évangélisation, avivée par la diffusion rapide de nouveaux mouvements religieux, en est un élément important mais focalise par trop le débat sur l'imposition de la religion aux Océaniens, s'appuyant notamment sur les liens forts que les missions entretinrent avec les administrations coloniales. Certains chercheurs tentent aujourd'hui de comprendre les dynamiques internes des christianismes océaniens, en les pensant à partir des contextes sociaux, politiques et économiques dans lesquels ils s'inscrivent. Les transformations induites par l'arrivée du christianisme ne sauraient donc se limiter aux bouleversements dans les croyances ou les cosmologies locales. Les rôles des missions, puis des Églises indépendantes et dirigées par les autochtones ont été centraux dans la diffusion de nouveaux modes de vie et de production, par la 
scolarisation, l'intronisation de nouveaux statuts de chefs, les discours sur la santé... Les religions chrétiennes implantées de plus ou moins longue date gagnent donc à être perçues dans une perspective endogène, qui permet de mieux saisir les comportements des Océaniens eux-mêmes (en référence à de nouvelles approches qui rejettent les modèles totalisants et mettent en avant le rôle des individus: agency, reprises d'initiatives...).

2 Les articles réunis dans ce volume s'inscrivent dans cette perspective, soulignant les liens et les continuités entre les cultes anciens et actuels, ou remettant en cause les présupposés essentialistes ou diffusionnistes qui expliquent généralement l'apparition des cargo cuits et l'implantation des nouvelles religions. En conclusion, les auteurs, pour mieux saisir les implications théoriques qu'entraîne l'étude des dynamiques religieuses et du changement culturel, n'hésitent pas à faire appel - fait hélas assez rare en anthropologie en général, et océaniste en particulier - aux théories sociologiques sur la religion et le pouvoir (Weber) ou sur l'action (Bourdieu). 